\title{
Hydrogeological characterization of peculiar Apenninic springs
}

\author{
FEDERICO CERVI ${ }^{1}$, MARCO MARCACCIO ${ }^{2}$, FRANCESCA PETRONICI $^{1} \&$ \\ LISA BORGATTI ${ }^{1}$ \\ 1 DICAM Dipartimento di Ingegneria Civile, Chimica, Ambientale e dei Materiali ALMA MATER STUDIORUM \\ Università di Bologna, Bologna, Italy \\ federico.cervi2@unibo.it
}

2 ARPA Emilia-Romagna Direzione Tecnica - Area Monitoraggio e Reporting Ambientale, Bologna, Italy

\begin{abstract}
In the northern Apennines of Italy, springs are quite widespread over the slopes. Due to the outcropping of low-permeability geologic units, they are generally characterized by low-yield capacities and high discharge variability during the hydrologic year. In addition, low-flow periods (discharge lower than $1 \mathrm{Ls}^{-1}$ ) reflect rainfall and snowmelt distribution and generally occur in summer seasons. These features strongly condition the management for water-supply purposes, making it particularly complex. The "Mulino delle Vene" springs (420 m a.s.l., Reggio Emilia Province, Italy) are one of the largest in the Apennines for mean annual discharge and dynamic storage and are considered as the main water resource in the area. They flow out from several joints and fractures at the bottom of an arenite rock mass outcrop in the vicinity of the Tresinaro River. To date, these springs have not yet been exploited, as the knowledge about the hydrogeological characteristics of the aquifer and their hydrological behaviour is not fully achieved. This study aims to describe the recharge processes and to define the hydrogeological boundaries of the aquifer. It is based on river and spring discharge monitoring and groundwater balance assessment carried out during the period 2012-2013. Results confirm the effectiveness of the approach, as it allowed the total aliquot of discharge of the springs to be assessed. Moreover, by comparing the observed discharge volume with the one calculated with the groundwater balance, the aquifer has been identified with the arenite slab (mean altitude of $580 \mathrm{~m}$ a.s.1.), extended about $5.5 \mathrm{~km}^{2}$ and located $1 \mathrm{~km}$ west of the monitored springs.
\end{abstract}

Key words groundwater; discharge monitoring; hydrogeological balance; northern Apennines, Italy

\section{INTRODUCTION AND STUDY SITE}

In the northern Apennines of Italy, aquifers hosted in flysch-rock units are to be considered as the main resources for water-supply purposes. These geological units are composed by the repetitive succession of arenite and pelite layers, and are generally crossed by several sets of joints, fractures and faults. If the sets are closely spaced and the arenite layers are predominant, a significant storage and rather high secondary permeability can be inferred. In all the cases, they are generally characterized by high velocity of depletion, that makes these systems extremely vulnerable to precipitation patterns/amounts and temperatures variations (i.e. to climate changes). In this context, a better understanding of their response to rainfall and snowmelt recharges is required. Due to their high degree of heterogeneity, the knowledge about the hydrogeological characteristics of these aquifers is not fully achieved and should firstly pass through a careful analysis of discharges from the springs. In-continuous monitoring of springs flowing out from these units is still uncommon. The "Mulino delle Vene" springs-site represents an opportunity to move forward in the understanding of the hydrogeological proprieties of these media. In fact, starting from 2012, a comprehensive investigation which involves in-continuous discharge, conductivity and temperature monitoring, together with monthly water sampling for chemical and isotopic analyses, has been carried out and is still ongoing. The springs originate at the bottom of a 50-m-long slope (elevation of $420 \mathrm{~m}$ a.s.l., Fig. 1). The outcrop is composed of arenites, which overlay almost impermeable marls (Fig. 1(a)). This slope is the southern termination of a continuous and poorly-deformed arenite slab with the bedding gently dipping towards the southeast (Fig. 1(b),(c)) that extends for about $5.5 \mathrm{~km}^{2}$ northward of the springs' site. The arenite unit thickness ranges from 35 to $100 \mathrm{~m}$ and is crossed by several conjugate sub-vertical faults (dipping NW-SE and NE-SW). Two springs (S1 and S2 in Fig. 1) were equipped with weirs since 1995, while others outflow diffusively on the slope. All the water then flows into the Tresinaro River, a few metres downslope of the springs. The discharge data are discussed in this paper. 


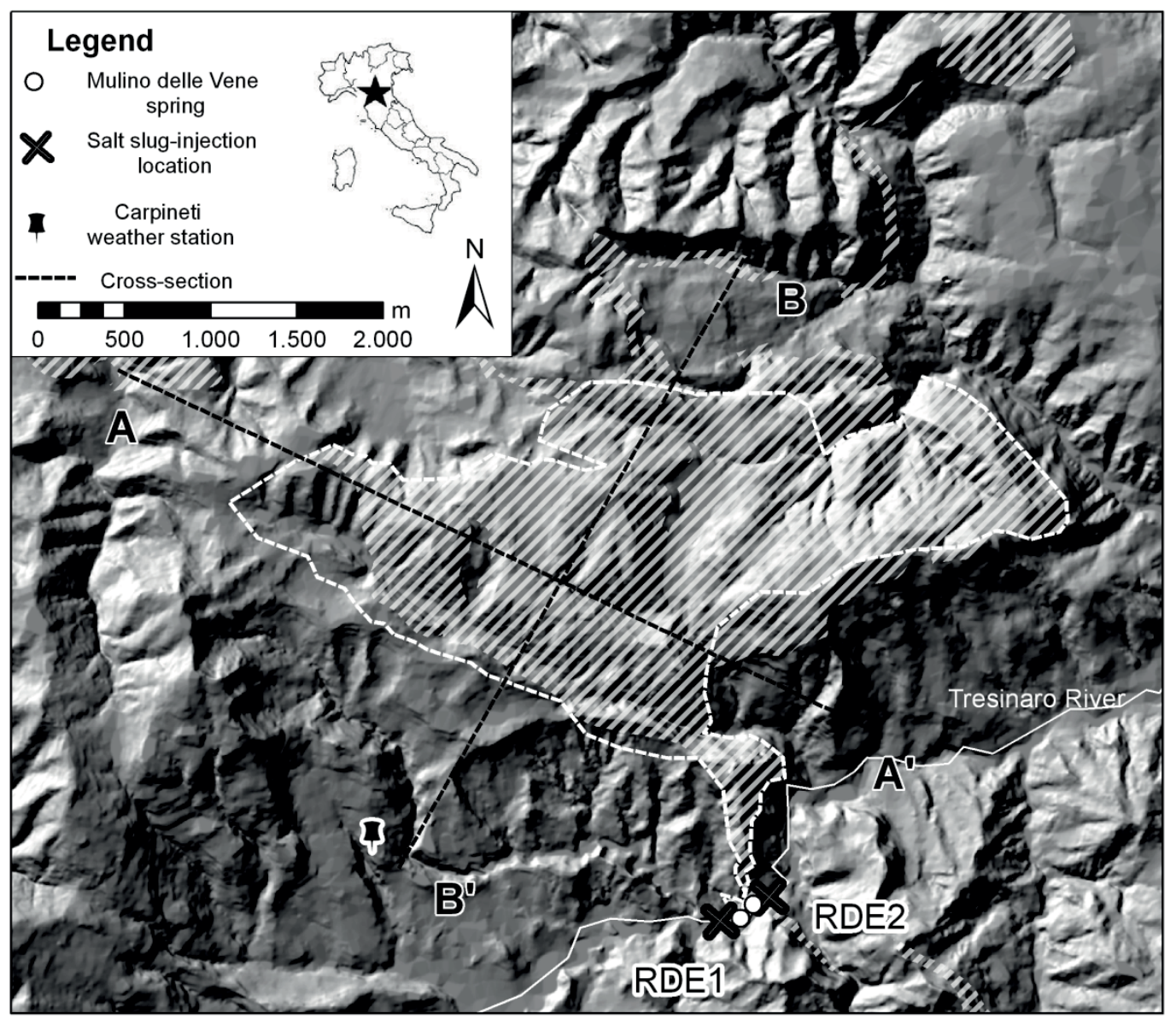

(a)

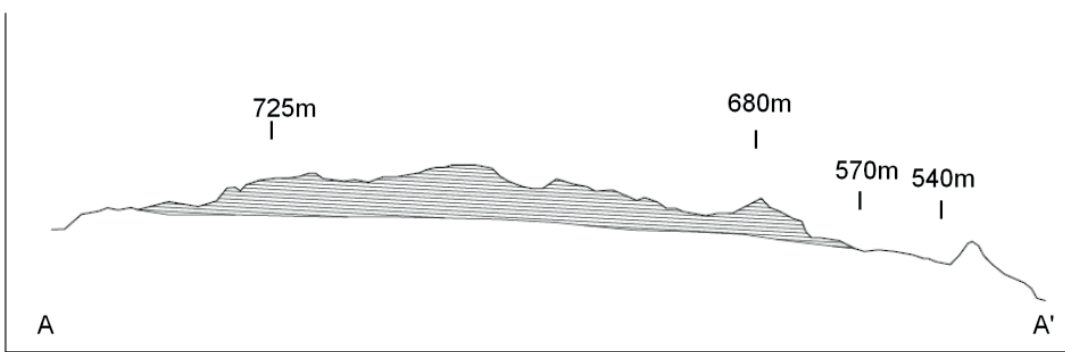

(b)

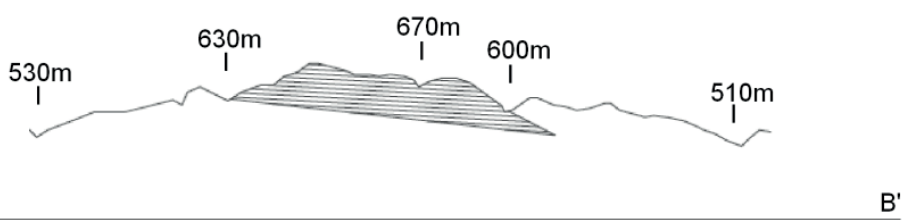

(c)

Fig. 1 Study area. (a) Mulino delle Vene springs area. The border of the arenite slab is identified by the white dashed line; the arenite unit outcrops also outside of the slab (white hatched lines area). (b), (c): simplified hydrogeological sections (not to scale). In grey arenitic units, in white marly units.

\section{METHODS}

Seven field campaigns were carried out monthly during the period 2012-2013 in order to obtain the total discharge flowing out from Mulino delle Vene springs, QTOT:

$$
Q T O T=Q 1+Q 2+Q 3
$$

This allowed all the aliquots of groundwater released by the springs $\mathrm{S} 1$ and $\mathrm{S} 2(Q 1$ and $Q 2)$ and the 
remaining ungauged aliquot $\mathrm{S} 3(Q 3)$ to be gathered. The latter has been calculated by estimating river discharges up and downstream of the springs' confluence (points RDE1 and RDE2 in Fig. 1(a) with discharge $Q R 1$ and $Q R 2$ ). By assuming no external water inflows between RDE1 and RDE2, the following water-balance can be written:

$$
Q R 2=Q R 1+Q T O T
$$

and $Q 3$ can be calculated as:

$$
Q 3=Q R 2-Q R 1-Q 1-Q 2
$$

In detail, $Q R 1$ and $Q R 2$ were assessed by the salt dilution method (Rantz et al. 1982). A hyperconcentrated solution was first prepared by diluting $0.5 \mathrm{~kg}$ of NaCl in $5 \mathrm{~L}$ of water and successively injected instantly (slug-injection) into the river. Conductivity was measured in-continuous $100 \mathrm{~m}$ downstream of the injection-point by using a conductivity-probe (STS DL/70/N MULTI); the acquisition-time was set at 6 seconds. No pools or back-water areas were present and the river streambed was characterized by the complete absence of alluvial deposits, therefore no subsurface seepage was possible. As reported by Day $(1976,1977)$, precisions are to be expected in the order of 4-7\%. In addition, S2 was equipped with an electric-transducer (STS DL/70/N) and the acquisition time was set at $1 \mathrm{~h}$; this permits the acquisition of in-continuous QTOT by linking it with $Q 2$ values whenever field data were available. The Interpolation model was selected after a goodness-of-fit comparison and error bounds corresponding to a $95 \%$ confidence interval ( $\pm 2 \mathrm{~s})$ are calculated. Effective rainfall was estimated using the Thornthwaite and Mather (1957) formula by considering the weather station located $1 \mathrm{~km}$ southwestward (Carpineti, Fig. 1). By processing the depletion part of the total spring discharge recession curve (i.e. the progressive decrease of QTOT which starts from the maximum peak Qmax and ends with the further minimum discharge Qmin, Fig. 2), the maximum springs yield W0 and the depletion (or exhaustion) coefficient $\alpha$ have been calculated. More in detail, recession curves from Apenninic springs are normally composed of an initial steeper part (falling curve), followed by a more gentle one (depletion curve). The latter is fed by the saturated portion of the aquifer, and it can be described by the exponential model proposed by Maillet (1905):

$$
\begin{aligned}
& Q t=Q 0 e^{-\alpha t} \\
& W 0=Q 0 \cdot 86400 / \alpha
\end{aligned}
$$

where 86400 are the number of seconds in a day. $\Delta \mathrm{W}\left(\mathrm{m}^{3}\right)$ is the emptying capacity of the system and indicates the volume of water resource outflowing from the spring between the beginning $(t=$ $\left.t_{0}\right)$ and the end $\left(t=t_{e}\right)$ of the recession period and therefore it represents the dynamic resource discharged in the absence of infiltration. Average renewal rate $\mathrm{T}_{\mathrm{RIN}}(\%)$ is the ratio between $\Delta W$ and $W 0$ and represents the percentage volume of resource renewed during the hydrological year. Further details about the procedures used to obtain all the parameters can be found in Civita (2005).

\section{RESULTS AND DISCUSSION}

The QTOT - Q2 plot reports the polynomial of degree 2 as well as the error bounds of the curvilinear regression (Fig. 2).

It can be noticed that for values of $Q 2$ greater than $40 \mathrm{Ls}^{-1}$, errors in the estimated $Q T O T$ progressively increase. In-continuous $Q T O T$ values from Mulino delle Vene springs are reported in Fig. 3, together with effective rainfall. The monitoring period embraces the hydrologic year 20122013, i.e. the period beginning with the recharge process taking place in October 2012 and ending with the low-flow at the beginning of November 2013. Discharges ranged between $460 \mathrm{Ls}^{-1}$ and less than $30 \mathrm{Ls}^{-1}$, with a mean value of $110 \mathrm{Ls}^{-1}$. During the low-flow period, S1 and S2 were almost dry and discharge was supplied to the Tresinaro River by the ungauged water aliquot alone. In more detail, groundwater discharge peaks in April and decreases until the beginning of November (i.e. the recession curve), following quite closely the effective rainfall pattern.

Aquifer recharge $(740 \mathrm{~mm}$ from the Carpineti raingauge, Fig. 1) is concentrated in the late Autumn (November) until the beginning of Spring (March-April), with a considerable aliquot (around 
19-22 March) which was related to a snowmelt of more than $1.5 \mathrm{~m}$ of cumulative snowcover, which is equivalent to $25-50 \mathrm{~mm}$ of water (see http://www.arpa.emr.it/sim/?telerilevamento/innevamento).

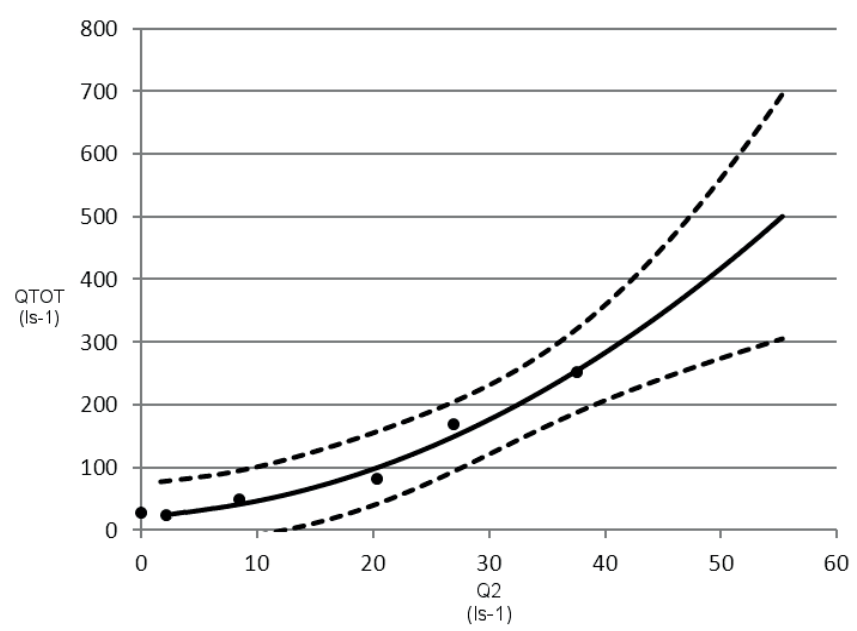

Fig. 2 Curvilinear regression curve (continuous line) obtained from the observed values of $Q T O T$ and $Q 2$ (filled dots). Error bounds (dashed lines) correspond to the $95 \%$ confidence intervals.

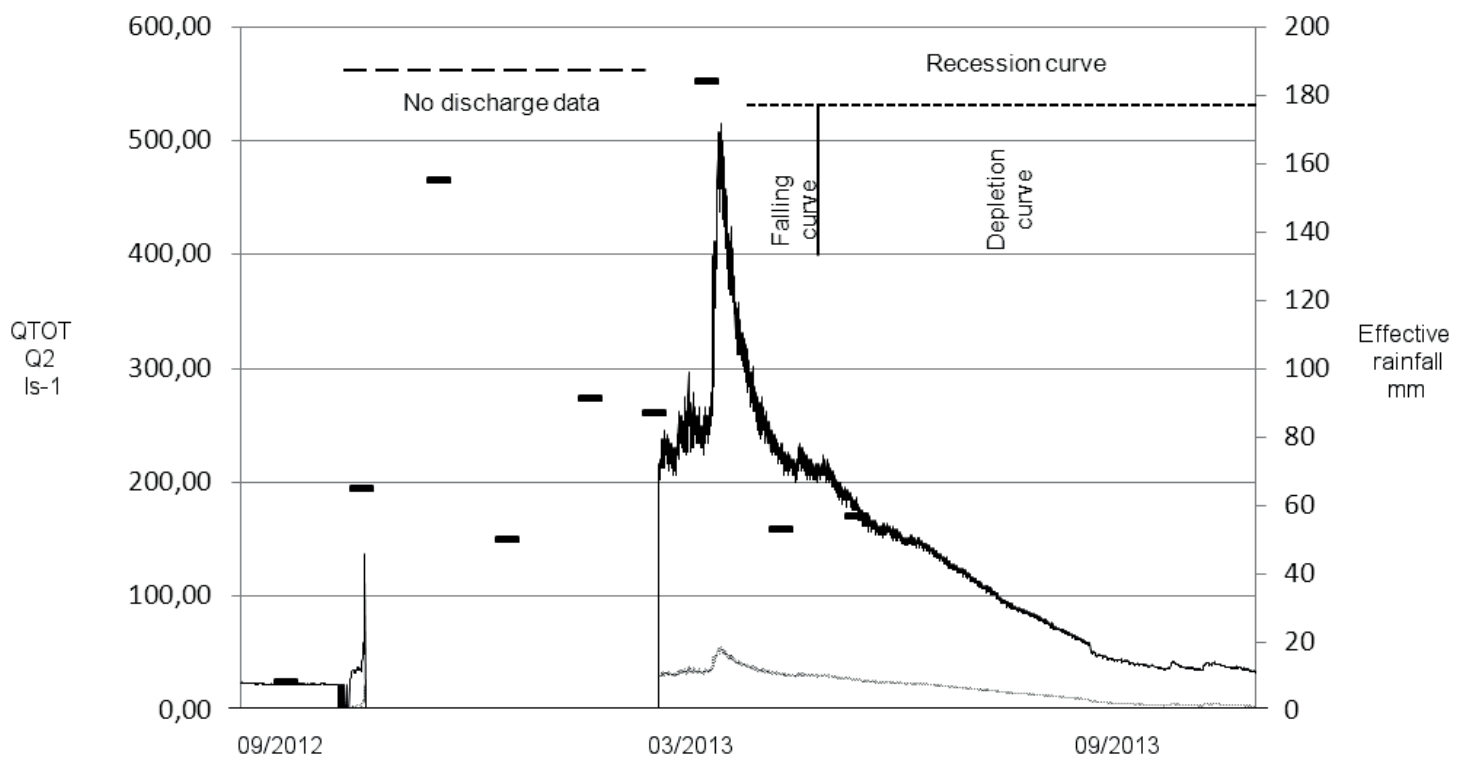

Fig. 3 Estimated $Q T O T$ (continuous black line; $\mathrm{Ls}^{-1}$ ) and observed $Q 2$ (grey dashed line; $\mathrm{Ls}^{-1}$ ) discharges from the hydrologic year 2012-2013 are reported together with monthly effective rainfall (black dashes; in mm). From 2 November 2012 to 11 March 2013 the electric transducer installed in spring S2 was out of work, therefore no discharge data are available for that period.

As anticipated in the Methods section, Mulino delle Vene recession curve is composed by an initial steeper part (falling curve in Fig. 3 during April), followed by a gentle one (depletion curve in Fig. 3, from May to the beginning of November). From a hydrogeological point of view, this represents the presence of two different portions within the aquifer, whose effects can be considered as superimposed at the beginning of the recession. In fact, discharge during the falling period was fed both by the infiltration from the upper portion of the aquifer, which is unsaturated in normal conditions, and the aquifer itself; in the latter discharge flows out following the Maillet (1905) formula, equation (4). In particular, the more permeable macro-fissures and the more opened fractures crossing the upper part of aquifer released quite quickly only the recently infiltrated water. The second part of the curve represents the contribution of fissures and fractures from the whole aquifer, and particularly of those characterized by lower permeability if compared with the 
aforementioned ones. Of course, the whole aquifer is active since the beginning of the recession curve and is characterized by an exhaustion coefficient $(\alpha)$ equal to $6 \times 10^{-3} \mathrm{~d}^{-1}$. This value is in the range of those found in other fractured flysch slabs in the northern Apennines (Corsini et al. 2009, Cervi et al. 2014) and allows for the quite fast depletion of the aquifer (QTOT from $220 \mathrm{Ls}^{-1}$ to about $28 \mathrm{Ls}^{-1}$ in 6 months). If no recharge had been supplied to the system at the beginning of autumn, the aquifer would have been completely emptied within 11 months. This period corresponds to the socalled "delay time" and it identifies the time required by the spring to zero the discharge (in this case, $Q T O T=0 \mathrm{Ls}^{-1}$ ). The maximum yield (W0) has been assessed as about $1.57 \mathrm{Mm}^{3}$, while the total discharge flowing out from the springs starting from the monitoring period was $3.34 \mathrm{Mm}^{3}$. The emptying capacity of the system $(\Delta \mathrm{W})$ is equal to $1.53 \mathrm{Mm}^{3}$, while $\mathrm{T}_{\mathrm{RIN}}=97 \%$. This means a complete renewal of the groundwater stored inside the aquifer (residence time equal to 160 days) and the almost complete absence of reserves that could provide water during drought periods.

The Carpineti weather station measured a mean air temperature of $12^{\circ} \mathrm{C}$ and a cumulative rainfall of $1180 \mathrm{~mm}$ from October 2012 to September 2013. By applying the Thornthwaite and Mather (1957) formula, a water surplus (i.e. effective rainfall) of $740 \mathrm{~mm}$ was available and it was supplied to the soil between November and April. This means that, even considering that all effective water could infiltrate, a recharge area with an extensions of $4.5 \mathrm{~km}^{2}$ was at least necessary. Actually, this value is consistent with the arenite slab extent $\left(5.5 \mathrm{~km}^{2}\right)$. Furthermore, by considering a more realistic value of the infiltration coefficient equal to $82 \%$ (as estimated by Vizzi (2013) for the same arenites), it can be assumed that all the arenite slab contributes to the Mulino delle Vene discharge. This fact, together with the results obtained by the recession curve analysis, leads to affirm that the aquifer is one and only and that its behaviour is strongly controlled by the network of discontinuities affecting the whole slab. Both the bedding planes attitude (monocline dipping to SE) and the set of secondary discontinuities tend to convey the flowpaths towards the springs, which are located in the lowest point of the system and can be considered as the only outlet of the aquifer.

\section{CONCLUSIONS}

The study has allowed the hydrogeological behaviour of one of the most important springs in the northern Apennines to be characterized. Total discharge QTOT has been assessed by means of salt slug-injections which were carried out repeatedly during the hydrologic year 2012-2013 up- and downstream of the springs confluences with the Tresinaro River. As QTOT has been linked to the in-continuous discharge values of one of the springs (S2), it was estimated on a continuous basis. The hydrogeological boundaries and the properties of the aquifer have been identified by coupling springs discharge recession analysis with a simplified hydrogeological balance which takes into account inflow (rainfall and snowmelt data) and outflow (QTOT). The recharge area has been identified as an arenite rock slab extending about $5.5 \mathrm{~km}^{2}$. Although the aquifer hosted inside the rock mass is characterized by a considerable dynamic storage $\left(\mathrm{W} 0=1.57 \mathrm{Mm}^{3}\right)$, the relatively high value of exhaustion coefficient $\left(\alpha=6 \times 10^{-3} \mathrm{~d}^{-1}\right)$ makes the depletion quite rapid in absence of recharge. This fact is commonly noticed in all springs discharging from flysch rock masses in the northern Apennines and makes them sensitive to changes in rainfall/snowmelt patterns/amounts and temperature fluctuations. Hydrological and hydrochemical monitoring is still ongoing, while further pumping tests in wells located in the arenite unit have been planned. This will allow the characterization of the aquifer to be further improved. Moreover, the response to effective rainfall changes will be verified thanks to the use of a 3D numerical model.

Acknowledgements This work was supported by the South East Europe Transnational Cooperation Programme "CC-WARE: Mitigating Vulnerability of Water Resources under Climate Change" (2013-2014). Authors wish to thank Francesco Ronchetti, Leonardo Vizzi (University of Modena and Reggio Emilia) and Demetrio Errigo (Environmental Agency of Emilia-Romagna Region) for the field-work support and the useful discussions. 


\section{REFERENCES}

Cervi, F., et al. (2014) Characterizing the recharge of fractured aquifers: a case study in a flysch rock mass of the northern Apennines (Italy). In: Proceeding of the IAEG XII CONGRESS Engineering Geology for Society and Territory, Torino, 2014 (submitted).

Civita, M (2005) Idrogeologia Applicata e Ambientale. CEA, Milano, 794 pp.

Corsini, A., Cervi, F. and Ronchetti, F. (2009) Weight of evidence and artificial neural networks for potential groundwater spring mapping: an application to the Mt. Modino area (Northern Apennines, Italy). Geomorphology 111(1-2), 79-87.

Day, T. J. (1976) On the precision of salt dilution gauging. J. Hydrol. 31, 293-306.

Day, T. J. (1977) Observed mixing lengths in mountain streams. J. Hydrol. 36, 125-136.

Maillet, E. (1905) Essais d'hydraulique souterraine et fluviale (Outline of underground and river Hydraulics) Lib Sci. A Herman, Paris, $218 \mathrm{pp}$

Rantz, S. E. et al. (1982) Measurement and computation of streamflow: Volume 1. Measurement of Stage and Discharge. U.S. Geological Survey Water Supply Paper 2175.

Thornthwaite, C. W. and Mather, J. R. (1957) Instruction and tables for computing potential evapotranspiration and the water balance. Publ. Clim. Drexel Inst. Technol. 10, 185-311.

Vizzi, L. (2013) Studio idrogeologico delle sorgenti Mulino delle Vene (Val Tresinaro). Master Degree Thesis, University of Modena and Reggio Emilia, 101 pp. (unpublished). 